\title{
Atomic Solid State Energy Scale: Universality and Periodic Trends
}

\section{in Oxidation State}

Brian D. Pelatt, ${ }^{\dagger}$ Robert S. Kokenyesi, ${ }^{,}$Ram Ravichandran, ${ }^{\dagger}$ Clifford B. Pereira, ${ }^{\#}$ John F. Wager,,$^{\dagger}$ and Douglas A. Keszler**

$†$ School of EECS, Oregon State University, Corvallis, OR 97331-5501

${ }^{\dagger}$ Department of Chemistry, Oregon State University, 153 Gilbert Hall, Corvallis, OR 97331-4003

\#Department of Statistics, Oregon State University, Corvallis, OR 97331-4606

*Corresponding Author: Douglas.Keszler@oregonstate.edu

\section{RECEIVED DATE}

\section{ABSTRACT}

The atomic solid state energy (SSE) scale originates from a plot of the electron affinity (EA) and ionization potential (IP) versus band gap $\left(\mathrm{E}_{\mathrm{G}}\right)$. SSE is estimated for a given atom by assessing an average EA (for a cation) or an average IP (for an anion) for binary inorganic compounds having that specific atom as a constituent. Physically, SSE is an experimentally-derived average frontier orbital energy referenced to the vacuum level. In its original formulation, 69 binary closed-shell inorganic semiconductors and insulators were employed as a database, providing SSE estimates for 40 elements. In this contribution, EA and IP versus $\mathrm{E}_{\mathrm{G}}$ are plotted for an additional 92 compounds, thus yielding SSE estimates for a total of 64 elements from the $s-, p-, d$-, and $f$-blocks of the periodic table. Additionally, SSE is refined to account for its dependence on oxidation state. Although most cations within the SSE database are found to occur in a single oxidation state, data are available for nine $d$-block transition metals and one $p$-block main group metal in more than one oxidation state. SSE is deeper in energy for a higher cation oxidation state. Two $p$-block main group non-metals within the SSE database are found to exist in both positive and negative oxidation states so that they can function as a cation or anion. SSEs for most cations are positioned above $-4.5 \mathrm{eV}$ with respect to the vacuum level, and SSEs for all anions are positioned below. Hence, the energy $-4.5 \mathrm{eV}$, equal to the hydrogen donor/acceptor ionization 
energy $\varepsilon(+/-)$ or equivalently the standard hydrogen electrode energy, is considered to be an absolute energy reference for chemical bonding in the solid state.

KEYWORDS: absolute solid state energy, ionization potential, electron affinity, electronegativity

\section{Introduction}

In this contribution, we report atomic solid-state energy (SSE) values for 94 elements in the periodic table and describe periodic trends in SSEs on the basis of oxidation state. Although the absolute energy of highest occupied and lowest unoccupied states is the first-order consideration in chemistry related to bonding, catalysis, electrochemistry, and electronic and optical devices, only recently has an absolute atomic SSE scale been established. ${ }^{1}$ In many ways, the SSE approach is a frontier-orbital-based formulation of electronegativity. ${ }^{2-4}$ SSE values are derived from an empirical database of binary inorganic compounds and their ionization potentials (IP), band gaps $\left(\mathrm{E}_{\mathrm{G}}\right)$, and derived electron affinities (EA) that have been measured with respect to the vacuum level. For a given binary compound, EA is associated with the energy of the cation, and IP defines the energy of the anion. Thus, the average frontier-orbital energy or equivalently the SSE of a given cation is estimated by averaging EAs of all of the binary compounds continuing that cation. Likewise, the SSE of a given anion is estimated by averaging IPs. Relative to electronegativity, SSE provides a universal advantage in describing the physical origin of the "power of an atom to attract electrons to itself in a chemical bond." Since SSE represents the average absolute frontier-orbital energy of an atom and electrons occupy the lowest possible energy levels, the "power of attraction" is simply related to the relative energy positioning of the SSEs. Atoms with SSE values deep in energy will strongly attract electrons and function as anions. Atoms with SSE values shallow in energy will tend to release electrons and function as cations. Atoms with similar SSEs will share electrons and thus form polar covalent bonds with the electrons polarized toward the atom with the deeper SSE. 
In our original formulation of SSE, ${ }^{1}$ EA and IP were plotted versus band gap $\left(\mathrm{E}_{\mathrm{G}}\right)$ for 69 closedshell binary inorganic semiconductors and insulators, yielding SSE estimates for 40 elements. Here, the database of IP, $\mathrm{E}_{\mathrm{G}}$, and EA values is expanded by an additional 92 binary inorganic compounds. This expansion leads to SSE estimates for each block - $s, p, d$, and $f$ - of the periodic table. A periodic table is presented with SSE estimates for 94 elements. 64 of these values have been directly derived from the empirical database, while 30 are estimated via a regression assessment of the correlation between SSE and Pauling electronegativity. SSE is also specified as a function of oxidation state. Cations and anions have SSEs that are consistently above and below $-4.5 \mathrm{eV}$, respectively, as measured with respect to the vacuum level. Atoms exhibiting both positive and negative oxidation states, e.g., $\mathrm{As}^{3+}$ and $\mathrm{As}^{3-}$, usually have SSEs positioned quite close to $-4.5 \mathrm{eV}$ with the cation SSE positioned above $-4.5 \mathrm{eV}$ and the anion SSE below. These observations suggest that the hydrogen donor/acceptor ionization energy $\varepsilon(+/-)$ at $4.5 \mathrm{eV}$, i.e., the standard hydrogen electrode energy, constitutes an absolute energy reference.

\section{Methods}

Literature values for IP and $\mathrm{E}_{\mathrm{G}}$ for 161 binary inorganic compounds are used to calculate SSE estimates for 64 elements. IP values from photoemission experiments set the valence-band maximum energy, and optical measurements of $\mathrm{E}_{\mathrm{G}}$ are then used to derive $\mathrm{EA}$, setting the conduction-band minimum energy. For a given cation, the available EA values are averaged to calculate SSE. For a given anion, IP values of a compound with that element are averaged to calculate SSE, although $d$-band transition metal compounds, compounds with $\mathrm{s}^{2}$ cations (i.e., $\mathrm{Tl}^{+}, \mathrm{Sn}^{2+}, \mathrm{Pb}^{2+}, \mathrm{As}^{3+}, \mathrm{Sb}^{3+}$, and $\mathrm{Bi}^{3+}$ ), and mixed cation oxidation state compounds, i.e., GaSe, InSe, and InTe, are excluded from consideration since IP for such a compound is likely to be at least partially cation-derived. IP, $\mathrm{E}_{\mathrm{G}}$, and EA values for all 161 compounds are collected in Table S1. SSEs, specified as a function of oxidation state for 64 elements, are collected in Table 1. A detailed discussion of SSE-scale fundamentals and relationships to electronegativity, chemical hardness, and ionicity is provided in our previous report. ${ }^{1}$ 


\begin{tabular}{|c|c|c|c|c|c|c|c|c|c|c|c|c|c|c|c|c|c|}
\hline $\begin{array}{c}\text { I } \\
\text { H } \\
-4.9\end{array}$ & & & & & & & & & & & & & & & & & $\stackrel{2}{\mathrm{He}}$ \\
\hline $\begin{array}{c}3 \\
\text { Li } \\
1.7\end{array}$ & $\begin{array}{c}4 \\
\mathrm{Be} \\
0.8\end{array}$ & & & $\begin{array}{c}\# \\
\text { Sy } \\
\text { +SSE }\end{array}$ & & $\begin{array}{c}\# \\
\text { Sy } \\
\text { SSE }\end{array}$ & & $\begin{array}{l}\# \\
\text { Sy }\end{array}$ & & & & $\begin{array}{c}5 \\
\text { B } \\
-2.2\end{array}$ & $\underset{-6.5}{6}$ & $\begin{array}{c}\mathbf{7} \\
\mathbf{N} \\
-7.0\end{array}$ & $\begin{array}{c}8 \\
0 \\
-8.0\end{array}$ & $\begin{array}{c}9 \\
\text { F } \\
-9.9\end{array}$ & $\begin{array}{c}10 \\
\mathrm{Ne}\end{array}$ \\
\hline $\begin{array}{c}\text { II } \\
\mathbf{N a} \\
0.9\end{array}$ & $\begin{array}{c}12 \\
M g \\
-1.7\end{array}$ & & & $\begin{array}{l}\text { Empirica } \\
\text { Cation/Ani }\end{array}$ & & Estimate & & No Data & & & & $\begin{array}{c}13 \\
\mathbf{A l} \\
-3.1\end{array}$ & $\begin{array}{c}14 \\
\mathrm{Si} \\
-2.4\end{array}$ & $\begin{array}{c}15 \\
P \\
-6.2\end{array}$ & $\begin{array}{c}16 \\
S \\
-6.3\end{array}$ & $\begin{array}{c}17 \\
\mathrm{Cl}\end{array}$ & $\begin{array}{c}18 \\
\mathrm{Ar}\end{array}$ \\
\hline $\begin{array}{l}19 \\
\mathrm{~K} \\
0.3\end{array}$ & $\begin{array}{c}20 \\
\mathrm{Ca} \\
-1.4\end{array}$ & $\begin{array}{c}21 \\
\text { Sc } \\
-0.9\end{array}$ & $\underset{-4.6}{22}$ & $\begin{array}{c}23 \\
V \\
-4.3\end{array}$ & $\stackrel{-4.8}{C r}^{24}$ & $\begin{array}{c}25 \\
M n \\
-3.0\end{array}$ & $\begin{array}{c}26 \\
\mathrm{Fe} \\
-4.7\end{array}$ & $\begin{array}{l}27 \\
\text { Co } \\
-3.5\end{array}$ & $\begin{array}{c}28 \\
\mathbf{N i} \\
-3.5\end{array}$ & $\stackrel{29}{\mathrm{Cu}}$ & $\begin{array}{c}30 \\
\mathbf{Z n}_{\mathbf{n}} \\
-3.7\end{array}$ & $\stackrel{\mathbf{G a}}{31}_{-3.8 \text { (III) }}$ & $\underset{-2.9}{32}$ & $\begin{array}{c}33 \\
\text { As } \\
-3.6 \text { (III) }\end{array}$ & $\begin{array}{c}34 \\
\text { Se } \\
-5.9\end{array}$ & $\begin{array}{l}35 \\
\mathrm{Br} \\
-7.1\end{array}$ & $\begin{array}{c}36 \\
\mathbf{K r}\end{array}$ \\
\hline $\begin{array}{c}37 \\
\mathbf{R b} \\
0.8\end{array}$ & $\begin{array}{c}38 \\
S r \\
-0.9\end{array}$ & $\begin{array}{c}39 \\
\mathbf{Y} \\
-1.9\end{array}$ & $\begin{array}{c}40 \\
\mathbf{Z}_{r} \\
-3.5\end{array}$ & $\begin{array}{c}41 \\
\mathrm{Nb} \\
-3.5\end{array}$ & $\begin{array}{c}42 \\
\text { Mo } \\
-4.6\end{array}$ & $\begin{array}{c}43 \\
\mathrm{Tc} \\
-4.6\end{array}$ & $\begin{array}{c}44 \\
\mathbf{R u} \\
-4.9\end{array}$ & $\begin{array}{c}45 \\
\mathbf{R h} \\
-3.6\end{array}$ & $\begin{array}{c}\text { 46 } \\
\text { Pd } \\
-1.7\end{array}$ & $\begin{array}{c}47 \\
\mathrm{Ag} \\
-4.1\end{array}$ & $\begin{array}{c}48 \\
C d \\
-4.3\end{array}$ & $\begin{array}{c}49 \\
\text { In } \\
-4.5 \text { (III) }\end{array}$ & $\begin{array}{c}50 \\
\text { Sn } \\
-4.4(\mathrm{IV})\end{array}$ & $\begin{array}{c}51 \\
\text { Sb } \\
-4.2 \text { (III) }\end{array}$ & $\begin{array}{c}52 \\
\mathrm{Te} \\
-6.1\end{array}$ & $\begin{array}{c}53 \\
I \\
-6.2\end{array}$ & $\begin{array}{c}54 \\
\times e\end{array}$ \\
\hline $\begin{array}{l}55 \\
\text { Cs } \\
0.6\end{array}$ & $\begin{array}{c}56 \\
\mathbf{B a} \\
-0.5\end{array}$ & $\begin{array}{c}57 \\
\mathrm{La} \\
-2.5\end{array}$ & $\begin{array}{c}72 \\
\text { Hf } \\
-3.4\end{array}$ & $\begin{array}{c}73 \\
\mathrm{Ta} \\
-3.7\end{array}$ & $\begin{array}{c}74 \\
W \\
-4.4\end{array}$ & $\begin{array}{c}75 \\
\mathbf{R e} \\
-4\end{array}$ & $\begin{array}{c}76 \\
\text { Os } \\
-4.9\end{array}$ & $\begin{array}{c}77 \\
\text { Ir } \\
-4.9\end{array}$ & $\begin{array}{c}78 \\
\mathbf{P t} \\
-2.2\end{array}$ & $\begin{array}{c}79 \\
\mathrm{Au} \\
-5.5\end{array}$ & $\begin{array}{c}80 \\
\mathrm{Hg} \\
-4.6\end{array}$ & $\begin{array}{c}8 \mathrm{I} \\
\mathrm{TI} \\
-3.3\end{array}$ & $\begin{array}{c}82 \\
\mathrm{~Pb} \\
-3.8\end{array}$ & $\begin{array}{c}83 \\
\text { Bi } \\
-4.3\end{array}$ & $\begin{array}{c}84 \\
\text { Po } \\
-4.3\end{array}$ & $\begin{array}{c}85 \\
\text { At } \\
-4.9\end{array}$ & $\begin{array}{c}86 \\
R n\end{array}$ \\
\hline $\begin{array}{c}87 \\
\text { Fr } \\
-0.3\end{array}$ & $\begin{array}{c}88 \\
\mathbf{R} \mathbf{a} \\
-0.9\end{array}$ & $\begin{array}{c}89 \\
\text { Ac } \\
-1.5\end{array}$ & $\begin{array}{l}104 \\
\text { Rf }\end{array}$ & $\begin{array}{l}105 \\
\text { Db }\end{array}$ & $\begin{array}{l}106 \\
\text { Sg }\end{array}$ & $\begin{array}{c}107 \\
\text { Bh }\end{array}$ & $\begin{array}{l}108 \\
\text { Hs }\end{array}$ & $\begin{array}{l}109 \\
M t\end{array}$ & $\begin{array}{l}110 \\
\text { Ds }\end{array}$ & $\begin{array}{l}\text { III } \\
\text { Rg }\end{array}$ & $\mathrm{C}_{\mathrm{n}}^{\mathrm{II}}$ & & $\begin{array}{l}114 \\
\text { FI }\end{array}$ & & $\begin{array}{l}116 \\
\text { Lv }\end{array}$ & & \\
\hline & & & $\mathrm{Ce}_{-4}^{58}$ & $\begin{array}{l}59 \\
\text { Pr } \\
-2.5\end{array}$ & $\begin{array}{c}60 \\
\mathbf{N d} \\
-1.6\end{array}$ & $\begin{array}{c}61 \\
\text { Pm }\end{array}$ & $\begin{array}{c}62 \\
S m \\
-1.7\end{array}$ & $\begin{array}{c}63 \\
\text { Eu }\end{array}$ & $\begin{array}{c}64 \\
\text { Gd } \\
-2.5\end{array}$ & $\begin{array}{c}65 \\
\mathrm{~Tb}\end{array}$ & $\begin{array}{c}66 \\
\text { Dy } \\
-3.3\end{array}$ & $\begin{array}{c}67 \\
\text { Ho } \\
-1.9\end{array}$ & $\begin{array}{c}68 \\
\text { Er } \\
-2.4\end{array}$ & $\begin{array}{c}69 \\
\mathrm{Tm}\end{array}$ & $\begin{array}{c}70 \\
\mathbf{Y b} \\
-1.7\end{array}$ & $\begin{array}{c}71 \\
\text { Lu } \\
-2\end{array}$ & \\
\hline & & & $\begin{array}{l}90 \\
\text { Th } \\
-2.1\end{array}$ & $\begin{array}{l}91 \\
\mathrm{~Pa} \\
-2.7\end{array}$ & $\underset{-3.4}{\mathbf{U}}$ & $\begin{array}{c}93 \\
\mathrm{~Np}^{2} \\
-2.1\end{array}$ & $\begin{array}{c}94 \\
\mathbf{P u} \\
-2.1\end{array}$ & $\stackrel{\text { Am }}{95}_{-2.1}$ & $\mathrm{Cm}_{-2.1}^{96}$ & $\begin{array}{c}97 \\
\mathbf{B k} \\
-2.1\end{array}$ & $\begin{array}{c}98 \\
\text { Cf } \\
-2.1\end{array}$ & $\begin{array}{l}99 \\
\text { Es } \\
-2.1\end{array}$ & $\begin{array}{c}100 \\
\mathrm{Fm} \\
-2.1\end{array}$ & $\begin{array}{c}101 \\
\mathrm{Md} \\
-2.1\end{array}$ & $\begin{array}{c}102 \\
\text { No } \\
-2.1\end{array}$ & $\begin{array}{l}103 \\
\mathbf{L r} \\
-2.1\end{array}$ & \\
\hline
\end{tabular}

Figure 1: Periodic table specifying atomic solid state energy (SSE) values (eV). SSEs are obtained from experimental data (blue for cations, red for anions) or estimated (gray) from known Pauling electronegativities (see text).

\section{Results and Discussion}

\section{Solid State Energy Periodic Table}

A periodic table specifying an atomic SSE for 94 elements is given in Figure 1. SSEs for elements color-coded blue (cations) or red (anions) are estimated from experimental data. SSEs colorcoded gray are estimated from Pauling electronegativity-SSE trends, as discussed in the section Solid State Energy Database Enhancement (see below).

SSE periodic trends are similar in many respects to those of electronegativity. Electronegativity tends to increase from left to right across a period, and to decrease down a column in the periodic table. Similarly, SSE tends to increase in magnitude when going from left to right across a period, and to decrease in magnitude when going down a column in the periodic table. Thus, a key difference between electronegativity and SSE is polarity; electronegativity is a positive quantity while SSE is a negative quantity, since it is a measure of energy with respect to a vacuum level reference. Electronegativity and $\mathrm{SSE}$ are also distinguished by their respective units, $(\mathrm{eV})^{1 / 2}$ and $\mathrm{eV}$. In the context of electronegativity, 
elements to the left (right) of the periodic table tend to be electropositive (electronegative). Likewise, elements to the left (right) of the periodic table tend to have shallow (deep) SSEs; electronic charge transfer occurs from atoms with shallow SSE to those with deep SSE. Hence, the SSE periodic table shown in Figure 1 is useful for emphasizing the close connection between SSE and electronegativity. This rendition, however, does not account for variation in SSE with oxidation state. Prior to exploring these oxidation-state trends, it is first necessary to briefly discuss expansion of the SSE database and the correlation between SSE and Pauling electronegativity that allows augmentation of the SSE periodic table by 30 elements.

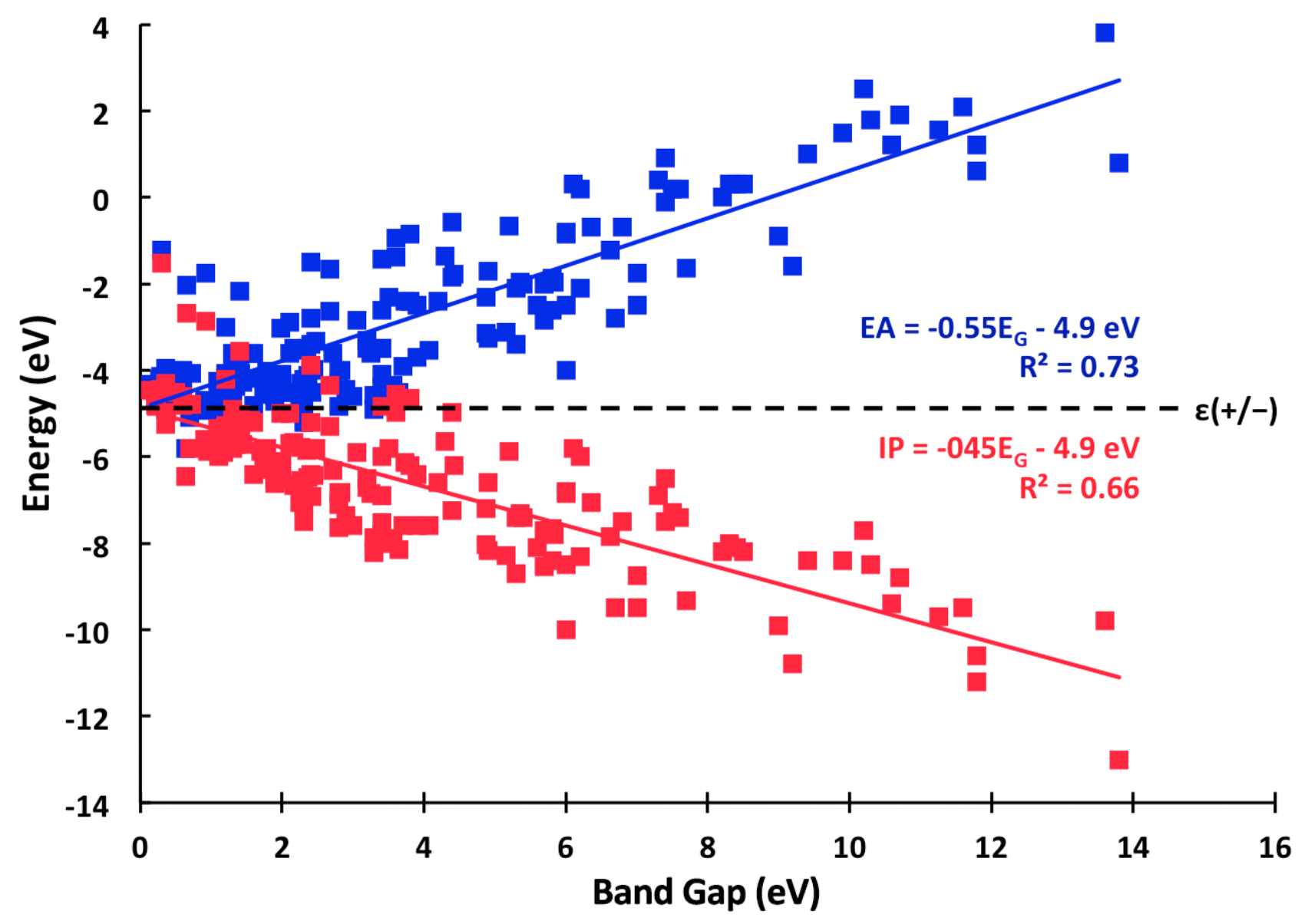

Figure 2: Electron affinity (EA, blue) and ionization potential (IP, red) versus energy band gap ( $\left.E_{G}\right)$ for 161 binary inorganic semiconductors and insulators. $\varepsilon(+/-)$ denotes the hydrogen donor/acceptor ionization energy or, equivalently, the standard hydrogen electrode (SHE) potential of electrochemistry as measured with respect to the vacuum level. 


\section{Solid State Energy Database Enhancement}

The database of EA, IP, and $\mathrm{E}_{\mathrm{G}}$ now includes 161 binary compounds (Table S1), encompassing materials with a wide variety of structures and properties, spanning elements of the $s, p, d$, and $f$ blocks, selected elements having multiple oxidation states. Straight-line correlations involving EA, IP, and $\mathrm{E}_{\mathrm{G}}$ are shown in Figure 2, revealing the same remarkable correlation previously demonstrated, ${ }^{1}$ preserved despite a $135 \%$ increase in the size of the source data. Regression lines for EA and IP intersect at -4.9 $\mathrm{eV}, 0.4 \mathrm{eV}$ below the hydrogen donor/acceptor energy $\varepsilon(+/-),{ }^{5}$ i.e., the standard hydrogen electrode (SHE) potential of electrochemistry as measured with respect to the vacuum level. ${ }^{6} \quad$ Most EA values are located above $-4.9 \mathrm{eV}$, while most IP values are located below $-4.9 \mathrm{eV}$. As a result, the band gap of the average semiconductor or insulator is approximately centered around $-4.9 \mathrm{eV}$. These observations lead to the existence of a universal energy reference that provides a means to correlate the energies of atoms in solids to standard reduction potentials of electrochemistry and to describe the nature of chemical bonding in the solid state. ${ }^{4}$

As a result of adding 92 new compounds to the analysis (Table S1), some atomic SSE estimates have been revised relative to our initial contribution. ${ }^{1}$ These changes, resulting both from expansion of the database and reinterpretation of original data sources, are discussed in Supporting Information. The SSE scale has been expanded by 24 elements primarily from the $d$ and $f$ blocks of the periodic table to a new total of 64 elements, allowing extension of the SSE concept to every block of the periodic table.

Table 1 lists SSE estimates for 64 elements. Since SSE is specified as a function of oxidation state and some elements are found to exist in multiple oxidation states, the number of entries (78) included in Table 1 exceeds the number of elements (64). Two SSE estimates are provided for the following five high oxidation-state elements, $\mathrm{V}^{5+}, \mathrm{Ta}^{5+}, \mathrm{Cr}^{6+}, \mathrm{Mo}^{6+}$, and $\mathrm{W}^{6+}$; alternative SSE estimates indicated within parentheses and obtained from reference [7] are discussed in the High Oxidation State SSE Estimates subsection. Recall that SSE is estimated for a cation (anion) by averaging EAs (IPs) available in the SSE database (see Tables S1 and S2) for the particular element under consideration. 
The SSE estimates for the 64 elements that are color-coded blue (for cations) and red (for anions) in Figure 1 are obtained in this manner.

Experimental IP and $\mathrm{E}_{\mathrm{G}}$ data have not been found for compounds that would allow derivation of SSE values for those elements missing from Table 1. By modifying our previously established relationship between Pauling electronegativity and SSE, ${ }^{1}$ we obtained SSE estimates for 30 additional elements (see Table S3). These values are derived from a regression fit (Figure 3) employing main group element SSEs from the expanded database. Values of Pauling electronegativity ${ }^{8}$ were substituted into the regression formula shown in Figure 3 to obtain estimates of SSE for the 30 elements that are coded gray in Figure 1.

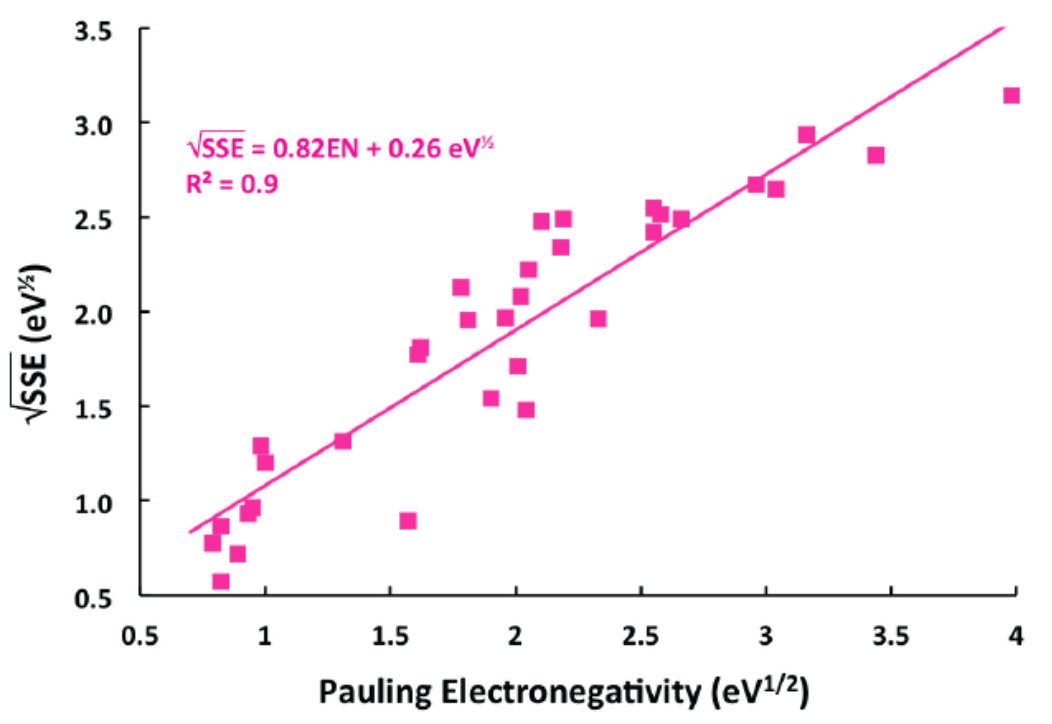

Figure 3: Regression line fit of the square root of the solid state energy (SSE) versus Pauling electronegativity for main group elements.

\section{Solid State Energy Oxidation State Considerations}

The premise that the chemistry of an element is adequately described by a single value of SSE or electronegativity is often misleading, since it does not account for the possibility that an element can exist in multiple oxidation states. Very early in the history of electronegativity, Sanderson suggested that electronegativity varies with oxidation state, ${ }^{9}$ a variation obscured when viewed through the lens of electronegativity. In contrast, this variation is self-evident when viewed through the lens of SSE, since 
SSE corresponds to the average energy of a frontier orbital, an energy that varies with oxidation state, becoming more negative as the charge of the atom becomes more positive, $c f$. ., Table 1.

From Figure 1 and Table 1, consider the Group 14 data set $\operatorname{SSE}(\mathrm{C}, \mathrm{Si}, \mathrm{Ge}, \mathrm{Sn})=-6.48,-2.37,-$ 2.4, $-4.26 \mathrm{eV}$. The SSE value $-6.48 \mathrm{eV}$ for $\mathrm{C}$ is peculiar in that it does not conform to an extrapolation of the trend established by the other three SSEs. The origin of this anomaly is simple. SiC is the only entry for $\mathrm{C}$ in the SSE database (Table $\mathrm{S} 1$ ). In SiC, $\mathrm{C}$ behaves as an anion with an oxidation state 4-. In contrast, SSEs for Si, Ge, and Sn correspond to the cationic 4+ oxidation state. Extrapolating a simple linear regression of SSEs for $\mathrm{Si}^{4+}, \mathrm{Ge}^{4+}$, and $\mathrm{Sn}^{4+}$ leads to the estimated $\operatorname{SSE}\left(\mathrm{C}^{4+}\right) \sim-1.0 \mathrm{eV}$, implying that EA for diamond should be $\sim-1.0 \mathrm{eV}$. Indeed, diamond is known to have a small EA, even reported to be negative, depending on how it is doped and how its surface is terminated. ${ }^{10}$ The estimated EA for diamond can be used to obtain an SSE-inspired band gap, ${ }^{1}$ the difference $\left[\operatorname{SSE}\left(\mathrm{C}^{4+}\right)-\operatorname{SSE}\left(\mathrm{C}^{4-}\right)=-1.0-\right.$ $(-6.5)]$ yielding $\mathrm{E}_{\mathrm{G}}=5.5 \mathrm{eV}$. This estimate agrees well with the reported band gap $\left(\mathrm{E}_{\mathrm{G}}=5.47 \mathrm{eV}\right)$ for diamond. $^{11}$

Consideration of the Group 14 data set provides further insight into some subtle aspects of SSE assessment. SSE range (R) and standard deviation (SD) for SSE values are given in Table S2. The SSE database (Table S1) contains one entry for carbon ( $\mathrm{SiC})$, three entries for silicon ( $\mathrm{SiC}, \mathrm{Si}_{3} \mathrm{~N}_{4}$, and $\mathrm{SiO}_{2}$ ), one entry for germanium $\left(\mathrm{GeO}_{2}\right)$, and nine entries for tin in its two different oxidation states $\left(\mathrm{Sn}^{2+}\right.$ : $\mathrm{SnBr}_{2}, \mathrm{SnCl}_{2}, \mathrm{SnO}, \mathrm{SnS}, \mathrm{SnSe}$, and $\mathrm{SnTe} ; \mathrm{Sn}^{4+}: \mathrm{SnO}_{2}, \mathrm{SnS}_{2}$, and $\mathrm{SnSe}_{2}$ ). Since only one entry is available for $\mathrm{C}$ and one for $\mathrm{Ge}$, no information related to SSE range and variation are available for these two elements. For $\mathrm{Si}$ and $\mathrm{Sn}, \mathrm{R}$ and $\mathrm{SD}$ are $\mathrm{SSE}\left(\mathrm{Si}^{4+}\right)=-2.37 \mathrm{eV}(\mathrm{R}=3.22 \mathrm{eV} ; \mathrm{SD}=1.63 \mathrm{eV})$; $\operatorname{SSE}\left(\mathrm{Sn}^{4+}\right)=-4.26 \mathrm{eV}(\mathrm{R}=0.49 \mathrm{eV} ; \mathrm{SD}=0.25 \mathrm{eV}) ; \mathrm{SSE}\left(\mathrm{Sn}^{2+}\right)=-3.86 \mathrm{eV}(\mathrm{R}=2.8 \mathrm{eV} ; \mathrm{SD}=1.21 \mathrm{eV})$. The range and variation of $\operatorname{SSE}\left(\mathrm{Sn}^{4+}\right)$ are quite small, while they are high for $\operatorname{SSE}\left(\mathrm{Si}^{4+}\right)$ and $\operatorname{SSE}\left(\mathrm{Sn}^{2+}\right)$. Some of this variability is undoubtedly associated with inaccurate measurement of IP or $\mathrm{E}_{\mathrm{G}}$, but much of it is associated with EA moving up and IP moving down, away from $-4.5 \mathrm{eV}$, as the cation-anion interatomic distance decreases. The chemical implications of this observation will be addressed in a forthcoming contribution. 


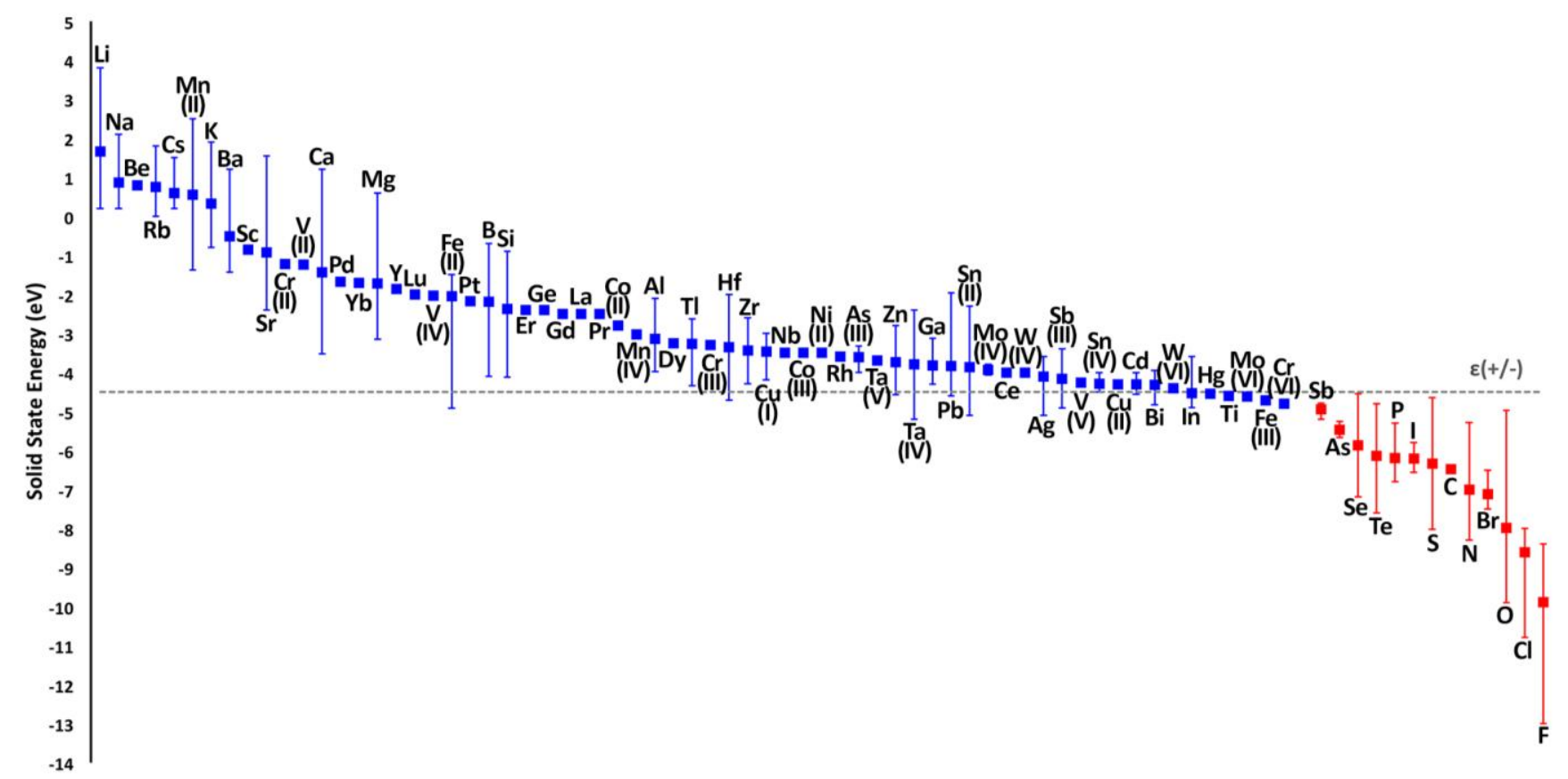

Figure 4: Atomic solid state energy (SSE) values arranged in descending energy order. The bar for some elements corresponds to the range or derived EA values for cations or measured IP values for anions. blue - cations, red - anions.

A plot of SSEs for the 78 entries in Table 1 are arranged in descending energy order in Figure 4. All anions are located below $-4.5 \mathrm{eV}$, and most cations are located above. Those anions with the deepest SSEs are considered to be highly electronegative, while cations with shallow SSEs are highly electropositive. All anions, included in the SSE database (Table 1), are found to exist in a single anion oxidation state. Although most cations in the SSE database also occur in a single oxidation state, IP and $\mathrm{E}_{\mathrm{G}}$ data were found for (i) nine transition metals in multiple oxidation states $\left(\mathrm{V}^{2+}, \mathrm{V}^{4+}, \mathrm{V}^{5+} ; \mathrm{Ta}^{4+}, \mathrm{Ta}^{5+}\right.$; $\left.\mathrm{Cr}^{2+}, \mathrm{Cr}^{3+}, \mathrm{Cr}^{6+} ; \mathrm{Mo}^{4+}, \mathrm{Mo}^{6+} ; \mathrm{W}^{4+}, \mathrm{W}^{6+} ; \mathrm{Mn}^{2+}, \mathrm{Mn}^{4+} ; \mathrm{Fe}^{2+}, \mathrm{Fe}^{3+} ; \mathrm{Co}^{2+}, \mathrm{Co}^{3+} ; \mathrm{Cu}^{+}, \mathrm{Cu}^{2+}\right)$, (ii) one p-block main group element in two oxidation states $\left(\mathrm{Sn}^{2+}, \mathrm{Sn}^{4+}\right)$, and (iii) two p-block main group elements in positive and negative oxidation states $\left(\mathrm{As}^{3-}, \mathrm{As}^{3+} ; \mathrm{Sb}^{3-}, \mathrm{Sb}^{3+}\right)$. The black bars associated with certain elements in Figure 4 cover the range from minimum and maximum values of EA or IP in the SSE database (see Table S2). The absence of bars for a given SSE indicates that only one value of EA or IP is available.

Of course, many more oxidation states exist beyond those listed in Table 1.31 of the elements included in Table 1 are considered to have a single common oxidation state, ${ }^{12,13}$ i.e., $\mathrm{Li}^{+}, \mathrm{Na}^{+}, \mathrm{K}^{+}, \mathrm{Rb}^{+}$, 
$\mathrm{Cs}^{+}, \mathrm{Be}^{2+}, \mathrm{Mg}^{2+}, \mathrm{Ca}^{2+}, \mathrm{Sr}^{2+}, \mathrm{Ba}^{2+}, \mathrm{Sc}^{3+}, \mathrm{Y}^{3+}, \mathrm{La}^{3+}, \mathrm{Zr}^{4+}, \mathrm{Hf}^{4+}, \mathrm{Ta}^{5+}, \mathrm{Ni}^{2+}, \mathrm{Ag}^{+}, \mathrm{Zn}^{2+}, \mathrm{Cd}^{2+}, \mathrm{B}^{3+}, \mathrm{Al}^{3+}$, $\mathrm{Ga}^{3+}, \mathrm{In}^{3+}, \mathrm{F}^{-}, \mathrm{Pr}^{3+}, \mathrm{Gd}^{3+}, \mathrm{Dy}^{3+}, \mathrm{Er}^{3+}, \mathrm{Yb}^{3+}$, and $\mathrm{Lu}^{3+}$ compared 33 elements that are considered to have multiple oxidation states, i.e., $\mathrm{Ti}^{2+, 3+, 4+}, \mathrm{V}^{2+, 3+, 4+, 5+}, \mathrm{Nb}^{4+, 5+}, \mathrm{Cr}^{2+, 3+, 4+, 5+, 6+}, \mathrm{Mo}^{3+, 4+, 6+}, \mathrm{W}^{4+, 6+}$, $\mathrm{Mn}^{2+, 3+, 4+, 6+, 7+}, \mathrm{Fe}^{2+, 3+}, \mathrm{Co}^{2+, 3+}, \mathrm{Rh}^{2+, 3+, 4+}, \mathrm{Pd}^{2+, 4+}, \mathrm{Pt}^{2+, 4+}, \mathrm{Cu}^{+, 2+}, \mathrm{Hg}^{+, 2+}, \mathrm{Tl}^{+, 3+}, \mathrm{C}^{4-, 2+, 4+}, \mathrm{Si}^{4-, 4+}, \mathrm{Ge}^{4-, 4+}$, $\mathrm{Sn}^{2+, 4+}, \mathrm{Pb}^{2+, 4+}, \mathrm{N}^{3-,+, 2+, 3+, 4+, 5+}, \mathrm{P}^{3-, 3+, 5+}, \mathrm{As}^{3-, 3+, 5+}, \mathrm{Sb}^{3-, 3+, 5+}, \mathrm{Bi}^{3+, 5+}, \mathrm{O}^{2-,+, 0.5-, 2+}, \mathrm{S}^{2-, 2+, 4+, 6+}, \mathrm{Se}^{2-, 4+, 6+}, \mathrm{Te}^{2-}$ ${ }^{, 4+, 6+}, \mathrm{Cl}^{-,+, 3+, 4+, 5+, 6+, 7+}, \mathrm{Br}^{-,+, 3+, 5+}, \mathrm{I}^{-,+5+, 7+}$, and $\mathrm{Ce}^{3+, 4+}$. Note that metallic elements exist only in positive oxidation states, while non-metal atoms can in general exist in either positive or negative oxidation states. $^{12}$

Consider SSEs for the two main group elements with data for both a positive and a negative oxidation state: $\operatorname{SSE}\left(\mathrm{As}^{3+}\right)=-3.61 \mathrm{eV}$ and $\operatorname{SSE}\left(\mathrm{As}^{3-}\right)=-5.47 \mathrm{eV}, \operatorname{SSE}\left(\mathrm{Sb}^{3+}\right)=-4.16 \mathrm{eV}$ and $\mathrm{SSE}\left(\mathrm{Sb}^{3-}\right)=$ $-4.94 \mathrm{eV}$. For both cases, SSE is above $-4.5 \mathrm{eV}$ for the cation and below for the anion. It appears that SSE is positioned relatively close to $-4.5 \mathrm{eV}$ for elements displaying this sort of behavior, i.e., which are capable of exhibiting both positive and negative oxidation states.

Next, consider SSEs for a representative sampling of the nine $d$-block metals with data for multiple oxidation states. Beginning with $\operatorname{SSE}\left(\mathrm{V}^{2+}\right)=-1.23 \mathrm{eV}, \mathrm{SSE}\left(\mathrm{V}^{4+}\right)=-2.03 \mathrm{eV}$, and $\mathrm{SSE}\left(\mathrm{V}^{5+}\right)=-$ $4.26 \mathrm{eV}$, it is clear that SSE is deeper with increasing oxidation state. A similar trend is obtained for chromium, i.e., $\operatorname{SSE}\left(\mathrm{Cr}^{2+}\right)=-1.22 \mathrm{eV}, \operatorname{SSE}\left(\mathrm{Cr}^{3+}\right)=-3.3 \mathrm{eV}$, and $\mathrm{SSE}\left(\mathrm{Cr}^{6+}\right)=-4.82 \mathrm{eV}$. This tendency for SSE to become deeper with increasing cation oxidation state is observed for eight of the nine multiple oxidation state d-block metals. Data for Ta are anomalous, since SSE is found to be slightly shallower in energy with increasing oxidation state, i.e., $\operatorname{SSE}\left(\mathrm{Ta}^{4+}\right)=-3.80 \mathrm{eV}$ and $\operatorname{SSE}\left(\mathrm{Ta}^{5+}\right)=-3.69$ eV. 


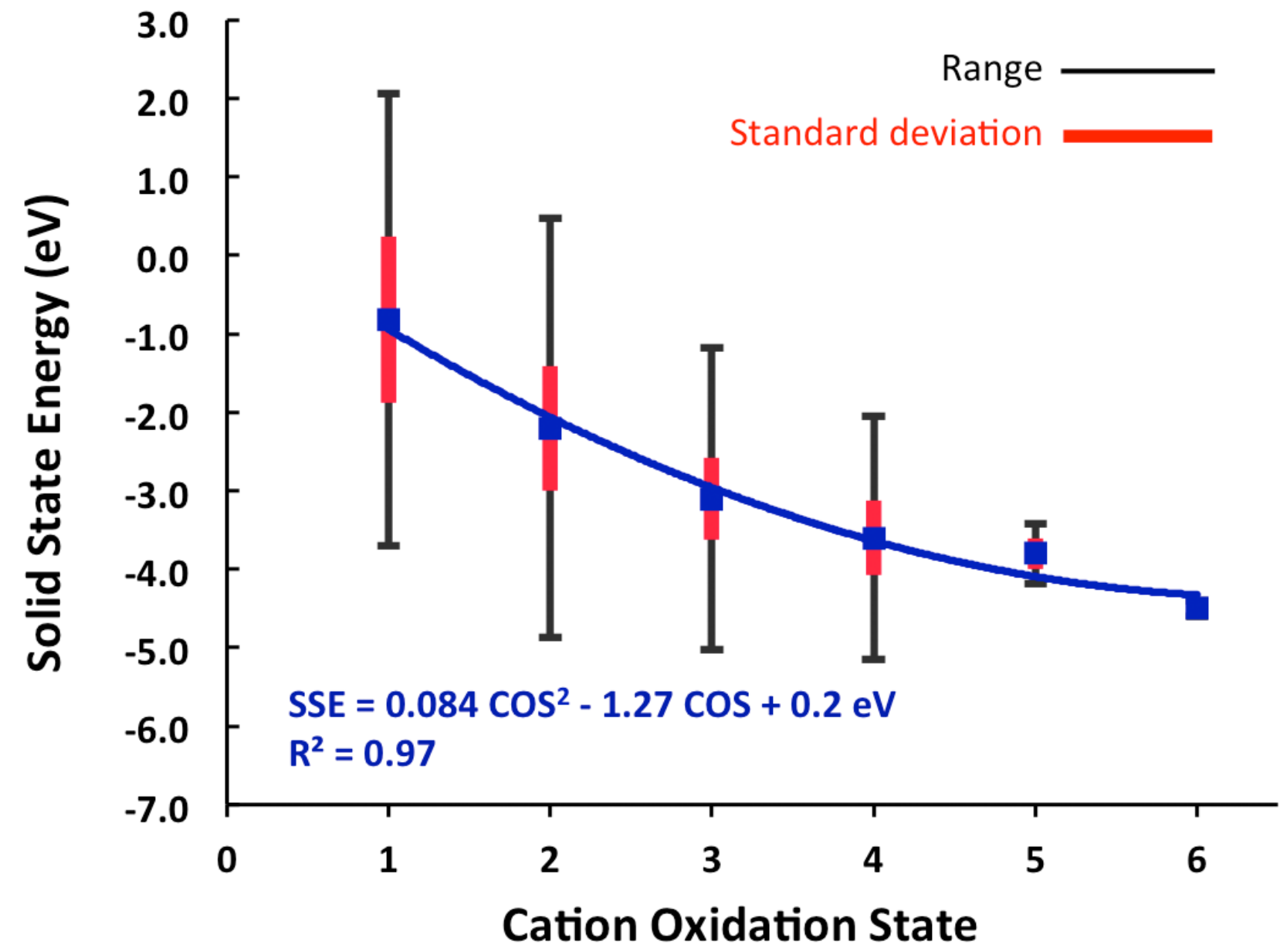

Figure 5: Average SSEs as a function of cation oxidation state (COS).

Average SSEs for cations in each oxidation state are listed in Tabe S4 and plotted in Figure 5. SSE trends to deeper energies with increasing oxidation state. Moreover, SSE appears to asymptotically approach $\varepsilon(+/-)$ at the highest oxidation state $6+$. The deeper energy with increasing oxidation state indicates that the frontier orbital is contracting with increasing oxidation state. Because the SSEs of cations in high oxidation states are closer in energy to anion SSEs than those of cations in low oxidation states, the bonding between highly charged cations and anions is expected to be more covalent. This covalency relaxes the actual charges of the cations in high oxidation states to values well below the formal oxidation state. ${ }^{14}$ We interpret the tendency for SSE to saturate near $\varepsilon(+/-)$ at the highest charge state of $6+$ as further evidence for the existence of a universal solid state energy reference.

Two aspects of Figure 5 merit further comment. First, the specified ranges and standard deviations of the 1+, 2+, 3+, and 4+ oxidation states shown in Figure 5 (and collected in Table S4) 
clearly indicate that the correlation shown in Figure 5 involves a large amount of variability. Thus, oxidation state alone does not determine SSE. Rather, oxidation state is only one of several chemical attributes that contribute to determining SSE values. Second, the SSE database includes only three entries each for the 5+ and 6+ oxidation states. Therefore, the small variability in SSE for these oxidation states is at least partially a consequence of having a limited set of data. In addition, EAs and IPs for most of the compounds containing cations in the $5+$ and $6+$ oxidation states remain unsettled. This topic is pursued in more detail next.

\section{High Oxidation State SSE Estimation}

The SSE values for a few of the high-oxidation cations require additional consideration. In our previous contribution on $\mathrm{SSE},{ }^{1}$ we employed the data from Ref. 7 for $\mathrm{V}_{2} \mathrm{O}_{5}, \mathrm{Ta}_{2} \mathrm{O}_{5}, \mathrm{CrO}_{3}, \mathrm{MoO}_{3}$, and $\mathrm{WO}_{3}$ to estimate SSEs for the high oxidation state ions $\mathrm{V}^{5+}, \mathrm{Ta}^{5+}, \mathrm{Cr}^{6+}, \mathrm{Mo}^{6+}$, and $\mathrm{W}^{6+}$. This analysis yielded the five SSEs shown in parentheses in Table 1 (corresponding EAs and IPs from Ref. 7 are shown in parentheses in Table S1). Several considerations motivated us to initially choose these data. First, the publication is relatively recent with IP and $\mathrm{E}_{\mathrm{G}}$ conveniently tabulated for a large number of oxides. Second, IPs were measured by careful in-situ photoemission measurements, which have been corroborated for $\mathrm{V}_{2} \mathrm{O}_{5}, \mathrm{MoO}_{3}$, and $\mathrm{WO}_{3}$ by other groups specializing in in-situ photoemission assessment. $^{15,16}$ Third, the very deep IPs $^{7}$ have been invoked to explain dramatic improvements in device performance that are found after an interlayer of $\mathrm{V}_{2} \mathrm{O}_{5}, \mathrm{MoO}_{3}$, or $\mathrm{WO}_{3}$ is inserted at the interface of an organic light-emitting device, an organic thin-film transistor, or an organic photovoltaic cell. ${ }^{7}$ Given the technological importance of this topic and the consistent set of experimental data available, it would appear that $\mathrm{EA}$, IP, and $\mathrm{E}_{\mathrm{G}}$ for $\mathrm{V}_{2} \mathrm{O}_{5}, \mathrm{MoO}_{3}$, and $\mathrm{WO}_{3}$ should be deemed as being well established. We have, however, not included these values in our current data base, because they are not entirely consistent with periodic trends and chemical observations.

Thus, although the photoemission community appears to be converging on the conclusion that EA, IP, and $\mathrm{E}_{\mathrm{G}}$ for $\mathrm{MoO}_{3}, \mathrm{~V}_{2} \mathrm{O}_{5}$, and $\mathrm{WO}_{3}$ are very similar, i.e., $\mathrm{EA} \approx-6.5 \mathrm{eV}, \mathrm{IP} \approx-9.5 \mathrm{eV}$, and $\mathrm{E}_{\mathrm{G}} \approx 3$ 
$\mathrm{eV},{ }^{7,15,16}$ these values of EA and IP are extraordinarily deep, which should lead to high chemical reactivity. For example, $\mathrm{EA}=-6.5 \mathrm{eV}$ corresponds to a standard reduction potential of $+2 \mathrm{~V}$. The compounds should be powerful oxidizing agents, but this behavior is not observed with these materials. For comparison, effective EA values for Group 5 oxides have been derived from electrochemical measurements, giving $\mathrm{V}_{2} \mathrm{O}_{5}(-4.7 \mathrm{eV}), \mathrm{Nb}_{2} \mathrm{O}_{5}(-4.6 \mathrm{eV})$, and $\mathrm{Ta}_{2} \mathrm{O}_{5}(-4.3 \mathrm{eV}) .{ }^{17}$ From the same analysis, EA for $\mathrm{WO}_{3}$ is $-5.2 \mathrm{eV}$, a deeper value than those observed for the Group 5 materials. ${ }^{17}$ Thus, the accuracy of the reported EA and IP estimates ${ }^{7}$ for all of the +5 and +6 high oxidation state oxides, i.e., $\mathrm{V}_{2} \mathrm{O}_{5}, \mathrm{Ta}_{2} \mathrm{O}_{5}, \mathrm{CrO}_{3}, \mathrm{MoO}_{3}$, and $\mathrm{WO}_{3}$, remains uncertain; the photoemission values and the associated SSE estimates are shown in parentheses in Tables S1 and 1, respectively. Having reliable SSE estimates for these five high oxidation state ions is critically important for elucidating chemical trends. For example, if the reported EA/IP values ${ }^{7}$ are used to estimate SSEs for the high oxidation state ions $\mathrm{V}^{5+}$, $\mathrm{Ta}^{5+}, \mathrm{Cr}^{6+}, \mathrm{Mo}^{6+}$, and $\mathrm{W}^{6+}$, the relationship between SSE and oxidation state, shown in Figure 5, appears to be linear (see Figure S1), leading to an unusual interpretation of the relationship between SSE and cation oxidation state (see the Alternative Figure 5 Plot subsection in Supporting Information).

Rather than estimating SSEs on the basis of the reported IP data, ${ }^{7} \mathrm{SSE}$ values for $\mathrm{V}^{5+}, \mathrm{Ta}^{5+}, \mathrm{Cr}^{6+}$, $\mathrm{Mo}^{6+}$, and $\mathrm{W}^{6+}$ have been obtained by using standard reduction potentials (acidic solutions) as assessed from Latimer diagrams (see Appendix 2 of reference [18]) which have been corrected to a vacuum level energy reference by subtracting $4.5 \mathrm{eV}$ from the standard reduction potential. This procedure to estimate SSEs for the five high oxidation state oxides under consideration, i.e., $\mathrm{V}_{2} \mathrm{O}_{5}, \mathrm{Ta}_{2} \mathrm{O}_{5}, \mathrm{CrO}_{3}, \mathrm{MoO}_{3}$, and $\mathrm{WO}_{3}$, allows a direct comparison between photoemission-derived SSE estimates obtained from a single compilation $^{7}$ and solution-based SSE estimates also obtained from a single compilation. ${ }^{18}$ As evident from Table 1, photoemission-derived SSEs are approximately $2 \mathrm{eV}$ deeper than solution-based estimates. 


\section{Universal Solid State Energy Reference}

In our original formulation of SSE, ${ }^{1}$ the intercepts of the linear-line fits of IP/EA vs. $\mathrm{E}_{\mathrm{G}}$ plots, equivalent to the plot in Figure 2, were found to be $-4.5 \mathrm{eV}$ with respect to the vacuum level. This energy is statistically equivalent to $-4.44 \mathrm{eV}$, the absolute electrode potential of hydrogen as established by the International Union of Pure and Applied Chemistry. ${ }^{6}$ Similarly, this $-4.5 \mathrm{eV}$ intercept is equivalent to the hydrogen donor/acceptor ionization energy, $\varepsilon(+/-) .^{5}$ In the expanded and updated SSE database presented herein, the intercepts of the IP/EA- $\mathrm{E}_{\mathrm{G}}$ plot (Figure 2) are found to be at $-4.9 \mathrm{eV}$ with respect to the vacuum level, rather than $-4.5 \mathrm{eV}$ as previously determined. Does this mean that the universal solid state energy reference is not actually positioned at $\varepsilon(+/-)$ ? At the $95 \%$ confidence level, linear regression analysis of the data yields upper and lower intercept energy bounds of -4.6 and -5.1 $\mathrm{eV}$, respectively, indicating that $\varepsilon(+/-)$ is slightly outside of these expected bounds. Close examination of the residuals arising from the linear regression fit reveals strong evidence for nonlinearity in the data as $\mathrm{E}_{\mathrm{G}}$ approaches zero. This nonlinearity can be modeled by employing a local regression (LOESS) nonparametric filter to smooth the data. A comparison of the linear regression fit and the LOESS fit is shown in Figure 6. Only consideration of the IP- $E_{G}$ data set is necessary, as regression analysis of the EA-E $E_{\mathrm{G}}$ data set is completely determined by correlation through the relationship $\mathrm{EA}=\mathrm{IP}-\mathrm{E}_{\mathrm{G}}$. When nonlinearity near $\mathrm{E}_{\mathrm{G}}$ is taken into account, the IP/EA-E $\mathrm{E}_{\mathrm{G}}$ intercept is indeed very close to $-4.5 \mathrm{eV}$ and $\varepsilon(+/-)$. From an SSE perspective, $-4.5 \mathrm{eV}$ is an important demarcation energy. Common cations and their frontier orbitals are positioned above $\varepsilon(+/-)$, and common anions are positioned below. In short, this $-4.5 \mathrm{eV}$ IP/EA-E $\mathrm{E}_{\mathrm{G}}$ intercept is a universal energy reference for chemical bonding in the solid state. Moreover, the nature of this energy reference appears to be intimately linked to the chemical and physical behavior associated with hydrogen in aqueous solutions and in the solid state. 


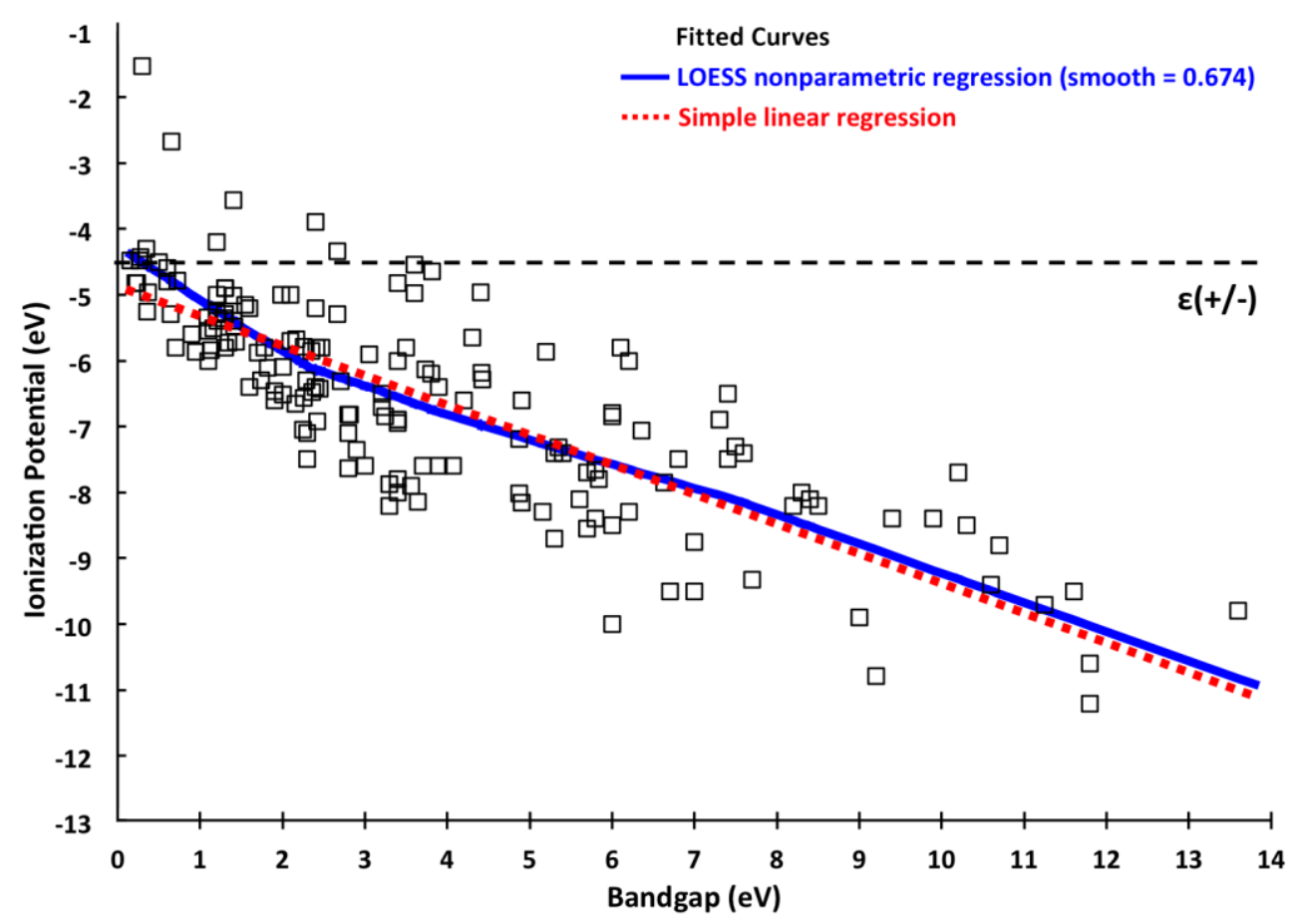

Figure 6: Ionization potential (IP) versus energy band gap $\left(E_{G}\right)$ for 161 binary inorganic semiconductors and insulators. A linear regression fit (red) and a nonlinear fit employing a local regression (LOESS) nonparametric filter (blue) are indicated.

Six cations in the SSE database, however, are positioned slightly below $\varepsilon(+/-)$, i.e., $\operatorname{SSE}\left(\operatorname{In}^{3+}\right)=$ $-4.53 \mathrm{eV}, \operatorname{SSE}\left(\mathrm{Ti}^{4+}\right)=-4.60 \mathrm{eV}, \operatorname{SSE}\left(\mathrm{Cr}^{6+}\right)=-4.82 \mathrm{eV}, \operatorname{SSE}\left(\mathrm{Mo}^{6+}\right)=-4.61 \mathrm{eV}$, and $\operatorname{SSE}\left(\mathrm{Hg}^{2+}\right)=-4.55$ $\mathrm{eV}$, so that they do not conform to the expected trend for a cation to be positioned above $\varepsilon(+/-)$. It is not clear whether these cation SSEs are a consequence of erroneous estimates or if cation positioning above $\varepsilon(+/-)$ is a strong periodic tendency that tolerates a few exceptions. Note that most of these anomalously positioned cations are either highly charged $\left(\mathrm{Ti}^{4+}, \mathrm{Cr}^{6+}, \mathrm{Mo}^{6+}\right)$ or involve cations that are rather large in size $\left(\mathrm{In}^{3+}, \mathrm{Hg}^{2+}\right)$, two attributes that tend to lead to a cation having a deep SSE.

\section{Conclusions}

The SSE database comprises a total of 161 binary inorganic compounds. The data have made possible the empirical estimation of atomic SSEs for 64 elements from the $s^{-}, p^{-}, d$ - and $f$-blocks of the periodic table. Atomic SSEs are assigned to 30 additional elements from regression fits to Pauling electronegativities. In addition, the SSE analysis has been extended to elements with multiple oxidation states. A nonlinear fit of IP vs. $\mathrm{E}_{\mathrm{G}}$ data reveals an intercept of $-4.5 \mathrm{eV}$. The frontier orbitals of cations are largely positioned about this energy, and those of anions are below. As $-4.5 \mathrm{eV}$ corresponds 
to the absolute energy of the standard hydrogen electrode, it carries a special significance for chemistry by directly connecting the energies of atoms in solids to standard potentials of oxidation-reduction reactions in solution. In addition, atomic SSEs provide a new, straightforward and quantitative approach to rationalizing and predicting periodic trends in chemical and physical properties.

ACKNOWLEDGMENT This material is based upon work by J.F.W. and D.A.K. supported by the National Science Foundation under Grant No. CHE-1102637 and by the work of B.D.P., R.S.K., and R.R. supported by the U.S. Department of Energy, Office of Science, Office of Basic Energy Sciences under Contract No. DE-AC36-08GO28308. 
TABLES.

Table 1: Solid State Energy (SSE) Values as a Function of Oxidation Number for 64 Elements

\begin{tabular}{|c|c|c|}
\hline Element & $\begin{array}{c}\text { Oxidation } \\
\text { Number }\end{array}$ & SSE (eV) \\
\hline $\mathbf{F}$ & -1 & -9.89 \\
\hline $\mathrm{Cl}$ & -1 & -8.61 \\
\hline $\mathrm{Br}$ & -1 & -7.12 \\
\hline 1 & -1 & -6.20 \\
\hline 0 & -2 & -7.98 \\
\hline$S$ & -2 & -6.31 \\
\hline Se & -2 & -5.86 \\
\hline Te & -2 & -6.14 \\
\hline $\mathbf{N}$ & -3 & -7.00 \\
\hline $\mathbf{P}$ & -3 & -6.20 \\
\hline As & -3 & -5.47 \\
\hline $\mathrm{Sb}$ & -3 & -4.94 \\
\hline C & -4 & -6.48 \\
\hline $\mathbf{L i}$ & +1 & 1.67 \\
\hline $\mathbf{N a}$ & +1 & 0.87 \\
\hline $\mathbf{K}$ & +1 & 0.33 \\
\hline $\mathbf{R b}$ & +1 & 0.75 \\
\hline Cs & +1 & 0.60 \\
\hline Be & +2 & 0.80 \\
\hline Mg & +2 & -1.72 \\
\hline $\mathrm{Ca}$ & +2 & -1.44 \\
\hline $\mathbf{S r}$ & +2 & -0.93 \\
\hline $\mathbf{B a}$ & +2 & -0.52 \\
\hline B & +3 & -2.18 \\
\hline Al & +3 & -3.14 \\
\hline $\mathbf{G a}$ & +3 & -3.82 \\
\hline In & +3 & -4.53 \\
\hline $\mathbf{T l}$ & +1 & -3.27 \\
\hline Si & +4 & -2.37 \\
\hline Ge & +4 & -2.4 \\
\hline Sn & +2 & -3.86 \\
\hline Sn & +4 & -4.26 \\
\hline $\mathbf{P b}$ & +2 & -3.84 \\
\hline As & +3 & -3.61 \\
\hline $\mathbf{S b}$ & +3 & -4.16 \\
\hline $\mathbf{B i}$ & +3 & -4.33 \\
\hline Sc & +3 & -0.85 \\
\hline $\mathbf{Y}$ & +3 & -1.86 \\
\hline $\mathbf{T i}$ & +4 & -4.60 \\
\hline
\end{tabular}




\begin{tabular}{|c|c|c|}
\hline $\mathbf{L a}$ & +3 & -2.5 \\
\hline $\mathbf{Z r}$ & +4 & -3.45 \\
\hline Hf & +4 & -3.36 \\
\hline $\mathbf{V}$ & +5 & $-4.26\left(-6.46^{7}\right)$ \\
\hline $\mathbf{V}$ & +4 & -2.03 \\
\hline $\mathbf{V}$ & +2 & -1.23 \\
\hline $\mathbf{N b}$ & +5 & -3.49 \\
\hline $\mathbf{T a}$ & +5 & $-3.69\left(-5.00^{7}\right)$ \\
\hline $\mathbf{T a}$ & +4 & -3.80 \\
\hline $\mathrm{Cr}$ & +6 & $-4.82\left(-6.75^{7}\right)$ \\
\hline $\mathrm{Cr}$ & +3 & -3.3 \\
\hline $\mathrm{Cr}$ & +2 & -1.22 \\
\hline Mo & +6 & $-4.61\left(-6.40^{7}\right)$ \\
\hline Mo & +4 & -3.94 \\
\hline $\mathbf{W}$ & +6 & $-4.41\left(-6.40^{7}\right)$ \\
\hline $\mathbf{W}$ & +4 & -4.00 \\
\hline Mn & +4 & -3.02 \\
\hline Mn & +2 & 0.56 \\
\hline $\mathbf{F e}$ & +3 & -4.71 \\
\hline $\mathbf{F e}$ & +2 & -2.05 \\
\hline Co & +3 & -3.50 \\
\hline Co & +2 & -2.80 \\
\hline $\mathbf{R h}$ & +3 & -3.6 \\
\hline $\mathbf{N i}$ & +3 & -3.50 \\
\hline Pd & +2 & -1.67 \\
\hline $\mathbf{P t}$ & +2 & -2.17 \\
\hline $\mathbf{C u}$ & +1 & -3.46 \\
\hline $\mathrm{Cu}$ & +2 & -4.30 \\
\hline Ag & +1 & -4.10 \\
\hline Zn & +2 & -3.73 \\
\hline Cd & +2 & -4.31 \\
\hline Hg & +2 & -4.55 \\
\hline $\mathrm{Ce}$ & +3 & -4 \\
\hline Pr & +3 & -2.5 \\
\hline Gd & +3 & -2.5 \\
\hline Dy & +3 & -3.3 \\
\hline Er & +3 & -2.4 \\
\hline $\mathbf{Y b}$ & +3 & -1.7 \\
\hline Lu & +3 & -2 \\
\hline
\end{tabular}




\section{REFERENCES}

1. Pelatt, B. D.; Ravichandran, R.; Wager, J. F.; Keszler, D. A. J. Am. Chem. Soc. 2011, 133, 16852.

2. Pauling, L. The Nature of the Chemical Bond, $3^{\text {rd }}$ ed.; Cornell University Press: Ithaca, 1960.

3. Huheey, J. E.; Keiter, E. A.; Keiter, R. L. Inorganic Chemistry, $4^{\text {th }}$ ed.; HarperCollins: New York, 1993.

4. Cox, P. A. Inorganic Chemistry; Springer: New York, 2000.

5. van de Walle, C. G.; Neugebauer, J. Nature 2003, 423 (6940), 626.

6. Trasatti, S. Pure Appl. Chem. 1986, 58.

7. Greiner, M. T.; Helander, M. G.; Tang, W-M.; Wang, Z-B.; Qiu, J.; Lu, Z-H. Nat. Mater. 2012, 11, 76.

8. Dean, J. A. Lange's Handbook of Chemistry, 15 ${ }^{\text {th }}$ ed.; McGraw-Hill: New York, 1999.

9. Sanderson, R.T. J. Chem. Ed. 1945, 31, 2

10. Diedrich, L.; Kuttel, O. M.; Aebi, L.; Schlapback, L. Surf. Sci. 1998, 418, 219.

11. Sze, S. M.; Ng, K. K. Physics of Semiconductor Devices, $3^{\text {rd }}$ ed.; Wiley: New York, 2007.

12. Chang, R. Chemistry, 8ed.; McGraw-Hill: Boston, 2005.

13. Nozaki, Y. Rare Earth Elements and their Isotopes in the Ocean, in Steele, J. H.; Turekian, K. K.;

Thorpe, S. A. (eds). Encyclopedia of Ocean Sciences, Vol. 4; Academic Press: London, 2001.

14. West. A. R. Solid State Chemistry and its Applications, $2^{\text {nd }}$ ed.; Wiley: Chichester, 2014.

15. Meyer, J.; Hamwi, S.; Kröger, M.; Kowalsky,W.; Reidl, T.; and Kahn, A. Adv. Mater. 2012, 24, 5408.

16. Klein, A. private communication.

17. Xu, Y. and Schoonen, M.A.A. Am. Mineral. 2000, 85, 543.

18. Shriver, D. F.; Atkins, P. W. Inorganic Chemistry, $3^{\text {rd }}$ ed.; W. H. Freeman: New York, 1999. 


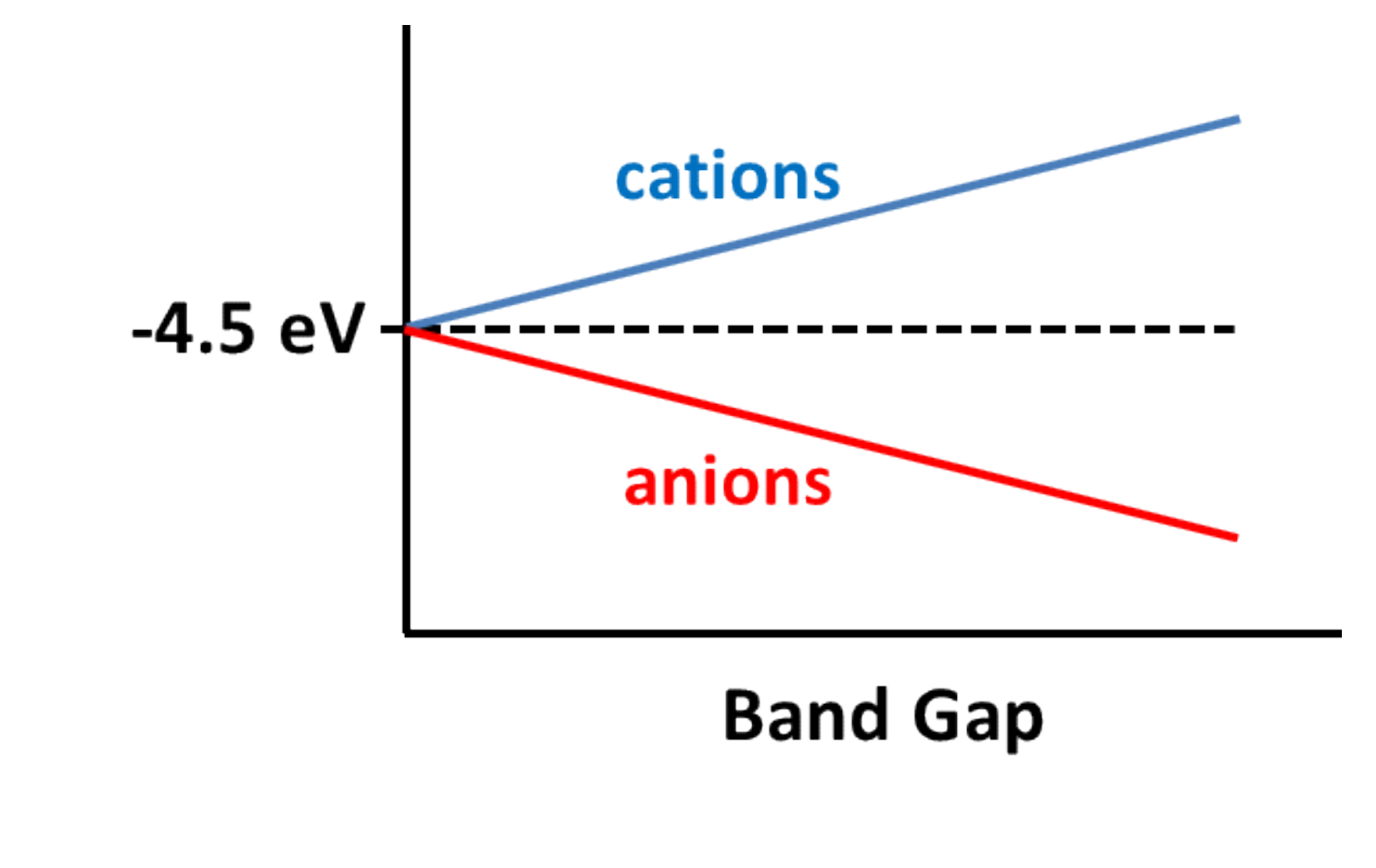

\section{Band Gap} .

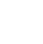
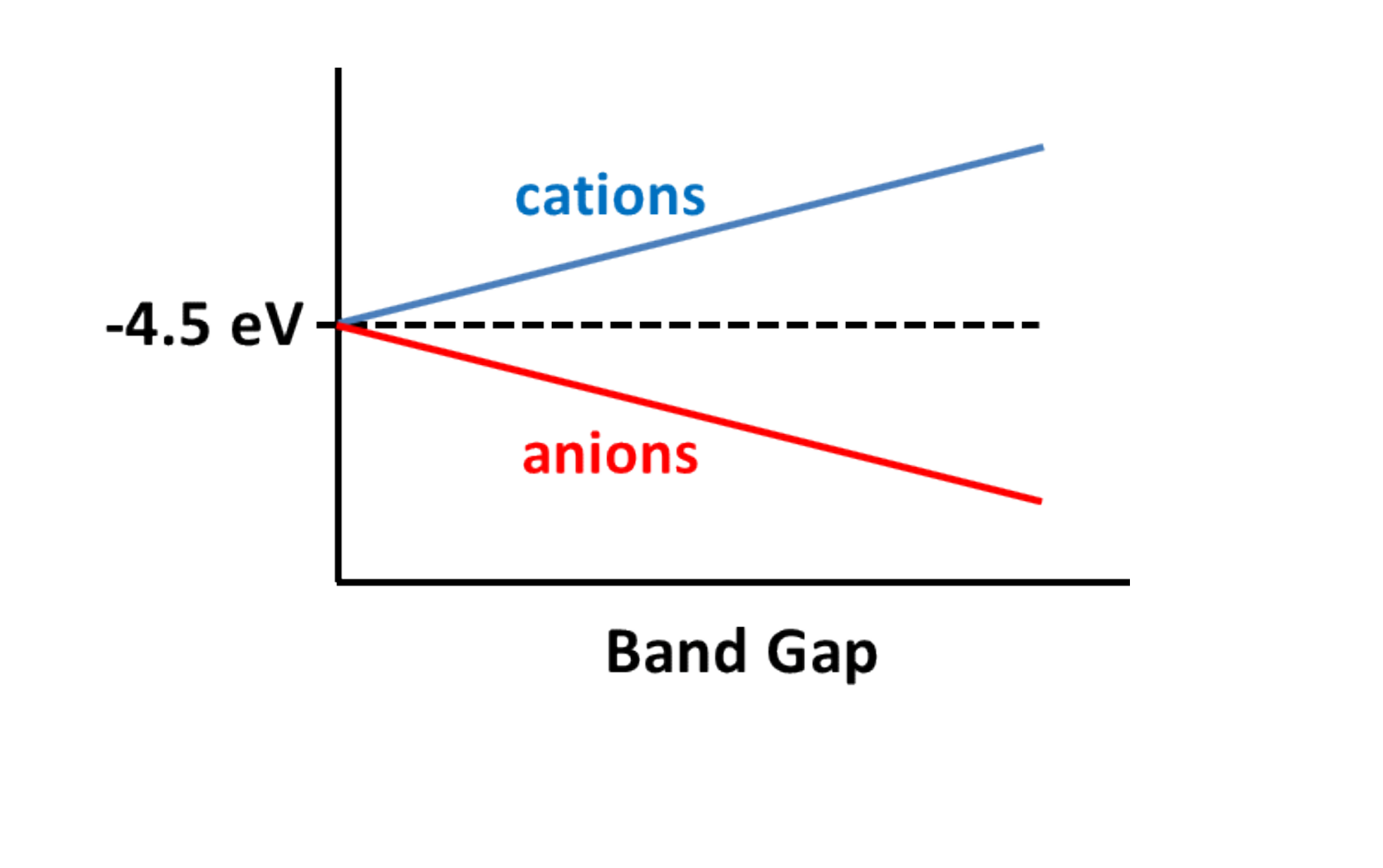